\title{
The Ambient Gaze: Sensory Atmosphere and the Dressed Body
}

\author{
Sara Chong Kwan
}

The sensing and sensuous body is more than the visual term 'appearance' would suggest. Georg Simmel alluded to this sensuous atmosphere of the dressed body in his writing on adornment:

The radiations of adornment, the sensuous attention it provokes, supply the personality with such an enlargement or intensification of its sphere: the personality so to speak, is more when it is adorned. ${ }^{\text {ii }}$

In their seminal definition of 'dress', Mary Ellen Roach-Higgins and Joanne B. Eicher propose that dress, which sits at the interface between the body and the macro-physical environment, is perceived by all the senses, not just sight ${ }^{\mathrm{iii}}$ but also, in varying degrees, touch, sound, smell and to a lesser extent taste. This chapter re-considers or rather, complicates 'the gaze' in relation to the dressed body, from the phenomenological perspective of the wearer. It challenges conventional approaches to 'male gaze' theory that tend to overstate the power of the gaze and the importance of appearance in forming dressed experience for the wearer. Such approaches fail to account for the actual lived agency of the wearer in resisting this social gaze and constructing their own sense of self through other sensory aspects of dress. A theory of the 'male gaze' tends to assume that this is the main system that defines how women dress and feel when dressed, yet empirical evidence presented in this chapter suggests that dressed experience for the wearer is much more complex than this - rather it is a multi-sensory act of self-creation, in which other meanings of dress also have importance. It departs from a notion of the wearer as passive object, moving the focus towards acknowledging the experience of the dressed self as subject: active in the process of meaning making. Alternative notions of 'dress as a sensory atmosphere for the body' and the 'ambient gaze' are proposed. These frameworks recognise the multi-sensory impressions that a dressed body makes in social life and the way in which all sensory modalities are in play when 'gazing' upon and interpreting the dressed appearance of others.

Dress is a practice, where social relations are played out, negotiated and constructed within different spaces and situations. It is, as Joanne Entwistle terms it, a 'situated bodily practice' ${ }^{\text {iv }}$ but furthermore, as will be argued in this chapter, it is a multi-sensory practice. Visual appearance is only one element, which together with other sensory dimensions, contributes to an overall 'atmosphere' or multi-sensory surround for the body. This notion of 'atmosphere' attends more holistically to the way clothing and 
the body mingle, in movement, through everyday life. In this context, atmosphere is constituted through appearance, movement, texture and touch, aromas and sounds, deportment, gestures and more intangible aspects such as the wearer's attitude, emotional mood, memories and imagination. Approaching the dressed body as atmospheric and the gaze as 'ambient' enables a consideration of these more intangible sensory aspects of dressed experience which also shape the meanings of dress for both wearer and observer.

The opening section of this chapter outlines the development of the theoretical framework that underpins this approach, one that integrates embodied, phenomenological and sensory theory, alongside an understanding of atmosphere as central to social life. Here the sensory gaps in Fashion and Dress Studies are highlighted, providing a critique to ocular-centric approaches that have tended to overlook the subjective perspective of the wearer. The following section discusses feminist critiques of the 'male gaze': a notion that privileges the visual over other senses - such as touch - in addition to devaluing the sensuous experience of women. Here the importance of understanding the senses as culturally constructed and in particular as gendered is stressed. The final section discusses how managing the sensory dimensions of everyday dress enables the wearer to negotiate the social gaze and mediate the impressions they make on others. Furthermore, it considers the contradictions between how the wearer may feel when dressed and how they may appear to others - problematizing the notion of fashion and dress as visual communication and questioning the power of the 'male gaze'. At the boundaries of the body, dress is positioned as providing a sensory atmosphere for the wearer, one that negotiates the tensions between private and public experience, between the meanings of dress for the observed and the observer.

Throughout this chapter, but particularly in the final section, the arguments will be underpinned with examples from interviews undertaken as part of my doctoral study into sensory engagement with everyday dress in a contemporary UK context. ${ }^{\mathrm{v}}$ This study was based on individual testimony, collected using life-world interviews with twenty participants both men and women, incorporating material culture analysis. I will highlight some of the ways in which the female and male participants expressed a self-conscious awareness of 'seeing and being seen' in particular social situations and public environments. Multi-sensory engagement with dress, involving visual but also tactile, auditory and olfactory elements played a role in the participants' negotiation of the gaze of others and the social structures, such as gender, that regulate rules of dressing. For example, the participants employed sensory dress strategies of inviting and deflecting the attention of others, such as hiding and/or revealing parts of the body or managing the body's scent and sound. These strategies provided an element of control over how 'visible' or 'invisible' they were to others and helped to mediate the 'impressions' that they made in social life. Additionally, more hidden, intimate and non-visual aspects of sensory dress experience, for example the touch of clothing on the skin, at times gave the participants a private 
sense of agency and resistance to perceived social expectations around appearance. This approach relies on two, interlinked understandings of the term 'sense': firstly as a specific 'sensation or feeling' and secondly as the action of 'making sense'. According to Vannini, Waskul and Gottschalk, 'The sense(s) is (are) both a reaching out to the world as a source of information and an understanding of the world so gathered'. vi

\section{Developing a sensory theoretical framework}

Dress is the first physical point of contact, the interface between the 'self' (as contained in the body) and the material, social and cultural world. Since the 1990s, fashion and dress studies have demonstrated how through dress and appearance, notions of the self and identity are explored by the wearer. Aspects of identity are expressed to others through clothing choices - constructed in accordance with or as a form of resisting, socially structured rules of dressing that link to cultural categories such as gender, age and class. The overwhelming focus of these studies has been towards only one of the five Western senses: sight. vii They have tended to theorise fashion and dress as a means of visual communication, in which dressed bodies are gazed upon, their meaning and 'identities' interpreted by others. Roland Barthes ${ }^{\text {viii }}$ proposed that fashion can be understood as a complex system of signs and following this, Alison Lurie ${ }^{\text {ix }}$ argued that clothes can be read as one would read a language. All of these accounts are based on visual aspects of dress - observations of either the item of dress or the appearance of the wearer when dressed. These approaches have privileged the perspective of the observer gazing upon the dressed bodies of others. The notion of 'the gaze', attended to in this volume, has been an important tool for critically unpicking the politics of dressed appearance and the implicit power of spectatorship. In particular this has been applied to gender politics in order to understand how the appearance of women is regulated through a disciplinary male gaze.

What these theoretical approaches have tended to overlook however, is the perspective of the wearer the 'other side' of the power of looking. That is, how the wearer experiences the gaze and, moreover, how they might employ individual agency to negotiate this disciplinary gaze. Dress and appearance form part of a social system that constructs and disciplines the body. ${ }^{\mathrm{x}}$ As a result, being dressed in everyday social life can be a highly self-conscious act, often involving a level of anxiety ${ }^{x i}$ as the wearer attempts to construct a look that will both fit in with the required norms of dressing to suit that situation, while also expressing individual preferences. However, the wearer can never be sure how their appearance will be interpreted by others, nor can the observer be sure of how the wearer feels.

More recently a body of work within fashion theory has established the importance of investigating the wearer's perspectives on dress. The work of Efrat Tseelon ${ }^{\text {xii }}$, Joanne Entwistle ${ }^{\text {xiii }}$, Shaun Cole ${ }^{\text {xiv }}$, Lou Taylor $^{\mathrm{xv}}$ Sophie Woodward ${ }^{\mathrm{xvi}}$ and Lucia Ruggerone ${ }^{\mathrm{xvii}}$ amongst others has begun to challenge purely 
visual interpretations of dressed appearance, addressing more fully the wearer's embodied perspective and experience. This departure contributes to a broader shift within the social sciences, arts and humanities towards an understanding of the body as the seat of perception and social and cultural meaning making. ${ }^{\text {viii }}$ This has its philosophical basis in phenomenology, in particular, that of Maurice Merleau-Ponty. This century has seen increased interest in phenomenology, which combined with continental philosophy has acted to critique the notion of Cartesian dualism - the separation and privileging of the mind over the body. By contrast, a phenomenological philosophy of embodiment views the mind as part of the body - as one 'unified person' - and knowledge as an integral aspect of bodily experience. In this way, knowledge of the world and the self is understood to come through lived experience. ${ }^{\text {xix }}$ Within sociology, a 'social constructivist' approach emerging from historical and anthropological work concerning the body has also challenged Cartesium dualism. This approach positions the body as a social and cultural phenomenon (as opposed to a biological entity), historically shaped by, and shaping, culture and social life and has established the body as a valid object of study within the social sciences and cultural studies. ${ }^{\mathrm{xx}}$

Colin Campbell's ${ }^{x x i}$ critique of Lurie's positioning of clothes as a 'language' suggests that observed meanings of dress are ambiguous and subjective, not necessarily shared between wearer and perceiver. Therefore, attempts to read what people wear as a form of language are unreliable and based on the observer's assumptions. Campbell argues that the focus on the visual pins 'meaning' to a singular visual appearance. ${ }^{\text {xxii }}$ Arguably, this has led to a denial or marginalisation of other accounts of meaning, in particular the wearer's own account, and their embodied, sensory experience. When dressed the wearer is seen and aware of being seen, but simultaneously feels the touch and movement of dress upon the body and is similarly sensitive to their body's scent and sound. As Entwistle has argued in her work on dress and embodiment, 'dress in everyday life cannot be separated from the living, breathing, moving body it adorns'. xxiii

As a form of material culture, what we wear is both a social, public activity and an intensely personal one, primarily due to its physical proximity to our bodies - we are in constant touch with our clothes. As previously stated, within Fashion and Dress Studies Merleau-Ponty's particular approach to phenomenology, which presents the sensory body as the seat of all perception and experience, has been increasingly influential in articulating the embodied nature of worn clothing. His influence is discussed by Llewellyn Negrin who argues that his work provides 'the theoretical tools with which to address fashion not simply as an aesthetic or symbolic phenomenon but as a haptic ${ }^{x x i v}$ experience' producing 'certain modes of bodily demeanour' ${ }^{x x v}$ This understanding of experience as centred in the lived - that is the 'feeling' and 'moving' - body, acknowledges the corporeality of being dressed. The logical progression from this embodied approach is to ask how the body experiences and perceives dress. Although fashion and dress scholarship has begun to increasingly focus on the phenomenological lived 
body, (utilising Merleau-Ponty in this respect), it has not fully engaged with his articulation of the nature of sensory perception in which the senses are interconnected and the body experiences a duality of seeing and touching. As Merleau-Ponty states: 'My body simultaneously sees and is seen. That which looks at all things can also look at itself and recognise, in what it sees, the 'other side' of its power of looking. It sees itself seeing; it touches itself touching: it is visible and sensitive for itself.' ${ }^{\text {xxvi }}$

Arguably, approaching dress as embodied practice necessitates an attention to how the wearer's body perceives dress, and that is through all the senses. There are hidden, sometimes taken for granted, sensory aspects of dressed experience - such as the smell of a perfume or the texture of a garment that have particular meanings, emotions or memories for the wearer. These aspects are usually not accounted for, particularly within theories of the gaze. How it feels to be dressed, in all its dimensions and in particular situations is an intrinsic, though not always easily researched or represented, aspect of daily life. Additionally, fashion and dress scholarship has not, until very recently engaged with the collection of interdisciplinary work around the senses which began to emerge at the end of the twentieth century. Initially funded by a grant from the Research Council of Canada, and based at Concordia University in Quebec, Anthony Synnott and David Howes, later joined by Constance Classen were central in developing the cultural history, anthropology and sociology of the senses, brought together through the establishment of the Centre for Sensory Studies in 2012. ${ }^{\text {xvii }}$ In Howes's account, the body experiences, comprehends and constructs the world through all its senses ${ }^{\text {xviii, }}$, thus culture shapes the senses and sensory activity shapes culture. How we use our senses and how we value the different senses and sensory behaviour and experience is culturally constructed and hierarchically arranged. The body's social and cultural experience, of which dress is one aspect, can in this way be seen as mediated through all sensory modalities. Following Howes, I argue that visual dimensions and visual perceptions of the dressed body are predicated on the other senses, which can work in tandem or at times in conflict with the visual.

At the turn of the twentieth century, the sociologist, Georg Simmel was one of the first to theorise the 'relationship of aesthetic and social forms' ${ }^{\text {xxix }}$ and also the relationship between the individual and social structures. This informed his work on the changing 'style' of fashionable clothing that articulated, for him, the 'paradox of fashion, of belonging and standing out simultaneously via sartorial methods and techniques'. ${ }^{\mathrm{xx}}$ Simmel also theorised the senses and at times these two areas of fashion and the senses collide in his writing. Simmel highlights the importance of sensation in social life, positioning micro sensory interaction as the building blocks or 'pulsating life' of larger social structures, as 'agents connecting individuals to social existence'. ${ }^{x x x i}$ This leads him to consider the sensory impressions a person makes through their 'radiations of adornment' - by which he means extraordinary dress that is designed to impress. Simmel's use of the term 'radiations' is suggestive of how all sensory aspects of dress - visual but also haptic, auditory and olfactory aspects - surround the wearer's body, creating a 
dressed atmosphere that is perceived by both wearer and observer and which play into this sense of 'belonging' and of 'standing out'. In his writing on the senses, Simmel explicitly outlined how a 'person's atmosphere' which makes a 'sensory impression' on others, is integral to social interaction. He argues that atmospheres pull people towards others, through instigating an 'instinct' or 'desire' to get to know them better through talking and interacting with them, and that this combination of sensory impression and knowledge 'become cooperatively, and in practical terms inseparably, the foundation of our relationship to that person'. xxxii In her sociological research into everyday 'atmospheres', Jennifer Mason has similarly argued that atmospheres in general play an integral part within social life:

a smell, a taste or a snatch of music that 'literally' (I use the term advisedly) transports you to another time and place and conjures its atmosphere in your mind, body and senses. Atmospheres bring into play not only human interactions, imaginaries, and sensations, but a wider more-than-human world of things, lives, rhythms, energies, elements, forces, places and times. Atmospheres are conjured and perceived in multisensory, extra-sensory, and ineffable ways. They can feel simultaneously tangible and intangible. ${ }^{\text {xxxiii }}$

Dress both reveals and conceals the body, changing its appearance and shape, but also its deportment and other sensory dimensions such as how it smells and sounds. In this way, appearance always involves a complex intertwining of sensory aspects and the perception of the onlooker is never purely a visual one. The gaze upon the dressed body employs vision but also an understanding of these other sensory aspects - an empathy towards the sensory experience of the wearer. When we observe another's dress, through drawing upon our own experience, we also bring to our gaze other sensory understandings. For example, we can imagine how the weight of the fabric and the cut of the garment might feel upon the body. This is embodied, sensory knowledge constructed from our own memories and lived experience of the sensory properties of clothing alongside understandings and associations that are socially constructed and mediated according to our individual culture, background and experience. ${ }^{\text {xxiv }}$ Arguably then, a more holistic and accurate way of conceptualising how these atmospheres of the dressed body are perceived by others, the 'sensuous attention' they provoke is through the notion of an 'ambient gaze'.

Photographs of clothing can also invite the viewer to imagine how they might feel to touch or to wear. As sensory ethnographer, Sarah Pink argues, even images have sensual qualities beyond the visual because they ignite the viewer's prior, embodied and sensory knowledge of the subject:

Photographs have the capacity to bring textures, surfaces and sensory experiences they evoke right up close to the reader: they both invoke embodied reactions and offer routes by which, via 
our own memories and subjectivities, we might anticipate what it feels like to be in another place. ${ }^{\mathrm{xxx}}$

In relation to images and the sensory materiality of clothing, this empathetic and ambient gaze was nicely articulated by the feminist philosopher, Iris Marion Young in her critique of the 'male gaze'. Young describes how, when looking at an advertising image of a woman in a wool suit, she imagines the feel of the wool swishing around her legs. ${ }^{\text {xxxvi }}$ As will be discussed in the following section, feminist philosophy, such as Young's, has played an important role in critiquing the notion of the 'male gaze' through reclaiming the sensory pleasures (and pains) that frame women's understanding of dress and fashion as part of their identities.

\section{Feminist philosophy, the gaze and the senses}

Drawing on continental philosophy, such as the writing of Luce Irigaray, ${ }^{x x x v i i}$ Young, in her seminal essay on women's embodied experience, considers women's intimate and emotional relationship with clothing and how an alternative and more representative way of talking about this might, for example, embrace the sense of touch more than sight. ${ }^{x x v i i i}$ The exclusive focus on 'the gaze' and more specifically a 'male gaze' that acts upon women, denies the subjective perspective and agency of women - who are more than passive objects on whom meaning is imposed, but are themselves active agents in the process of meaning making. Young questions how hierarchical values are imposed upon different types of sensory experience. There are parallels here between the hierarchical structuring of gender and that of the senses. The way that sensory aspects of dress are discussed in a western cultural context and in fashion theory is hierarchically structured, with vision taking prominence. This privileging becomes self-perpetuating. Because non-visual aspects of dress have been assigned less cultural importance, they are less often articulated and therefore become more difficult to articulate. Ruggerone has proposed that a new paradigm is required to investigate the everyday affective (material and immaterial) encounters with clothing, arguing that, 'because these practices are continually flowing events (becomings), their meaning can only be partially captured by interpretative/linguistic discourses'. ${ }^{\text {xxxix }}$ In my study, at times the participants struggled to clearly explain in words, non-visual aspects of their sensory engagement with dress, often reverting to hand gestures, such as rubbing their fingers together, to denote a texture or looking upwards as they 'imagined' the sensation but could not find the right words.

In Daniel Miller's view, the gendering of clothing is related to a 'denigration of surfaces' (clothing being a surface or covering for the body) as 'superficial', in contrast with the profound nature of the 'real’ person inside or abstract and ‘deep’ political thought: 
This denigration of surfaces has been part of the denigration of clothing and, by extension, of those said to be particularly interested in clothing, often seen as women, or blacks or any other group that thereby come to be regarded as more superficial and less deep. ${ }^{\mathrm{xl}}$

Here, there are also parallels to be made between the gendering of 'fashion' as female and the gendered hierarchy of sensory modalities that Howes describes as follows:

In the West the dominant group - whether it be conceptualized in terms of gender, class or race - has conventionally been associated with the supposedly 'higher' senses of sight and hearing, while subordinate groups (women, workers, non-Westerners) have been associated with the socalled lower senses of smell, taste and touch. ${ }^{\text {xli }}$

There is a contradiction apparent between these two examples of gender hierarchies, one that reveals them as nonsensical constructs, which as Miller suggests, can be used by one group to put down another. On the one hand, as Miller points out above, women are still denigrated as superficial, linked to an over concern with appearance, yet if sight is designated a 'higher' sense, it would logically follow that appearance should be highly valued. However, this contradiction is then overcome through further layering of hierarchies, such as the denigration of 'surface'.

While Young does not deny the existence of a patriarchal gaze that positions women as objects to be admired and denigrated in equal measure, she nevertheless argues that female experience of dress and fashion is much more than this: 'There is a certain freedom involved in our relation to clothes, an active subjectivity not represented in the male gaze theory'. ${ }^{\text {xli }}$ Rather, female experience of dress employs the pleasures of touch, bonding and fantasy in the active reimagining of the self. The way that dress touches and shapes the body is not merely expressive of cultural ideas or social structures, nor is it purely a pursuit for sensory and aesthetic pleasure. It is, as fashion theorists such as Elizabeth Wilson, ${ }^{\text {xliii }}$ Young and Agnès Rocamora ${ }^{x l i v}$ have argued, a complex mix of the two. As Wilson points out, the control of women's bodies through fashion and dress and their resulting subordination has been a 'source of concern to feminists, both today and in an earlier period', but she also acknowledges that this concern needs to be balanced with fashion's role as an active and liberating form of creative, self-expression, albeit an ambiguous one. ${ }^{\text {lv }}$

To give an example that illustrates this complexity, one of my participants, Pamela described how the touch of dress can indeed be a liberating force. She had a vivid, sensual memory of the first, flimsy silk bra she wore as a young woman in the 1950s. This signalled a profound sensory change from the girdle style 'roll-on' rubber underwear that she had previously worn (and her mother's generation still wore). She said: 
This feeling of just two thin bits of fabric over your boobies, you know, which was caressing you actually. I mean, it was really lovely. It was sumptuous. Once you put those on you couldn't go back to the others, so that also had something to do with the clothes, the freedom...

Having described the initial tactile pleasure of wearing the bra, Pamela then reflected on its loose, free structure and as a result, the more intangible and emotional sense of 'freedom' she experienced when wearing it. Pamela suggested that this might link to a social and moral sense of moving away from what she described as the 'chastity' and 'control mechanism' of the girdle. As Mark Paterson points out in his historical work on touch, tactile and haptic knowledge relates to objects but also to the space around the body: 'The feeling of cutaneous touch when an object brushes our skin is simultaneously an awareness of the materiality of the object and an awareness of the spatial limits and sensations of our lived body'. ${ }^{\text {xvi }}$ Pamela's sensation of breaking free from the boundaries restricting and disciplining her body alludes to wider socio-cultural changes that were taking place at the time as social rules relaxed and some of the younger generation began to reject previous social conventions and styles of dressing. It further demonstrates the importance of haptic aspects of clothing in both restricting and liberating the social body and the role of sensuous pleasure in enabling the wearer to know - and then potentially to transform - the way in which they position themselves in society.

Fashion, in the second half of the twentieth century has provided a means for resisting social structures and dominant identities. Research into these sartorial forms of resistance, such as subcultural style, have demonstrated the role fashion and dress plays in enacting change in individual subjectivities and in turn, broader social life. As Kaja Silverman states: If [...] clothing not only draws the body so that it can be seen, but also maps out the shape of the ego, then every transformation within a society's vestimentary code implies some kind of shift within its ways of articulating subjectivity. ${ }^{x l v i i}$ Deviant appearance is the visual enactment of social change. If then, as Simmel argues, sensory micro experience provides the building blocks of larger social life, we can begin to consider how the multi-sensory experience of clothing, not just its appearance, can also provide a means of resisting and negotiating the disciplining social gaze of others, which ultimately affects social and cultural change. Paul Sweetman has argued, in relation to subcultural identity, that fashion and style are not purely visual statements. The feel of clothing against the body, the way it makes the wearer move and act, that is, how clothing shapes a 'particular habitus' also helps ‘to shape both individual and group subjectivities'. ${ }^{\text {xlviii }}$

Remaining open to a fuller range of sensory knowledge and experience, allows us to move beyond the focus on dress and fashion as appearance and therefore explore the complexities of the relationship between the wearer and their clothes. This relates to male as well as female experience. As will be 
demonstrated in the following empirical examples, while gender shapes particular sensory experience, it is not only women who have a complex multisensory relationship with their clothing.

\section{Sensory dress strategies: Negotiating the social gaze}

How dress items looked and their own appearance when dressed were important daily considerations for the participants in my study, framed by aesthetic preferences and a self-conscious awareness of how others might perceive them within social situations. All of the participants acknowledged the need to dress appropriately and to take into account how other people might interpret their outfits in relation to social conventions and expectations of what they should look like, but they did not always comply with this need and sometimes challenged or subverted it.

Related to this body consciousness, in my interviews dress was, at times, used by the participants to pull in their bodies, to reshape them in an attempt to make their bodies both look and feel good. Managing these haptic sensations of dress could provide - like managing appearance - a means of conforming to but also negotiating the pressures from wider social structuring forces and discourses, which included normative and ideal notions around body shape and appropriate dressing. For example, one participant, James, collected and loved to wear American workwear. He talked in detail about the fabrics and how they felt to the touch, the structure of the garments and how they felt on. In this way, touch was central to how these items connoted, for James, a rather nostalgic sense of 'authenticity', 'toughness' and 'masculinity'. He told me that he often wore a particular peacoat - a heavy woollen double breasted coat traditionally worn by sailors - for smarter, social occasions:

When I put it on, it's got shape. It's almost like you have to fit the coat. The coat is not particularly forgiving to you. 'No. This is the shape I'm gonna be' (Laughter). And you kind of sort of have to deal with that...It's almost like it's made out of cast iron. I love the rigidity of it...

Here, James' body is affected. He changed to 'fit' the coat, not the other way round. The coat transformed the way he moved about the world, his deportment and attitude. It made him feel, act and possibly appear more contained and formal - and more 'masculine'. His body is disciplined not only through the perceived gaze of others, relating to how he thinks he should look, but also by the structure and feel of the coat on his body. Yet, while James' body is being disciplined, this is a physical sensation that he experienced as pleasurable.

In a different example, Robert illustrated the importance of haptic sensation in relation to his sense of self. Here I am using the term 'haptic' to describe how the whole body experiences and is affected by 
the feel of dress moving against, touching or pressing upon the body. Robert, who was born in the 1950s, remembered being forced to wear shorts as a schoolboy - which he hated with a passion - how the sensation of pulling on long trousers for the first time felt like a transition into manhood. He described how the very fabric itself seemed softer and of a better quality against the skin, which contributed to the physical sensation of having grown up and gained importance in the world. This is a type of sensory experience, in this instance haptic, that was felt intimately by Robert and had personal significance within his life relating to his specific social, cultural and life situation at the time. Wearing shorts had both private haptic and public visual meaning - he looked more grown up to others within society and he himself could sense this transition to adulthood. In this instance, both the visual and the haptic aspects of his dressed body are confirming the social rules that are guiding Robert's bodily sense of transition. This experience became a powerful sensory memory for Robert that framed his appreciation of the agency clothing could hold for him.

One of the main strategies employed to negotiate the gaze was through inviting and deflecting the attention of others by managing the sensory dimensions of their dress, such as hiding and/or revealing parts of the body or changing the body's scent and sound. These strategies provided an element of control over how 'visible' or 'invisible' they were or to put it in a multi-sensory way, helped to mediate the 'impressions' that they made on others in social life. For example, the sound of shoes was at times used by various participants to create impact or blend in within a social situation. Ryan illustrated this, when he discussed his brogues: 'Yeah. I've got a pair of brogues that I sometimes wear for work. Sometimes I love the noise that they make. And sometimes I hate it.' He said he liked it when 'I've got a spring in my step and I'm feeling bold and I'm in a look-at-me mode'. In this way, aural dimensions of clothing, like visual dimensions, can be seen to contribute to an individual's 'presentation of self' xlix providing a means to manage feelings of self-confidence and self-consciousness. As a result, the sound of clothing can have an important effect on how a person inhabits a social space, whether making them stand out or blend in, garner negative, positive or a confused response from others. Another participant, Corin stated that he did not want to draw attention to himself, so he was happy that his shoes were quiet. He said, 'I like to creep around unnoticed so I kind of - they (the soles) are quite soft'. Karen also echoed a similar sentiment when she stated:

not in England, but when I was in Poland, I already attracted loads of attention from people because I wear colourful stuff, and I was bullied and making sound would make it even worse so yeah, I never really wear stuff like dresses that make sound.

Alternatively, the sound of clothing can intensify the impression a person makes on others. One participant, Pamela, remembered how the sound of her clothing helped to signal her 'arrival' and domination at an important fashion awards event in Milan. In order to make an impression, she had 
purchased for the occasion an unusual raffia jacket. She described it as 'perfect' and 'magical', standing out against the classic, conservative style favoured by many Milanese. Pamela described the jacket in all its sensory dimensions, how the shiny black raffia 'sparkled', and was 'crunchy' yet 'malleable'. She expanded on the sound, 'It rustled, it rustled. So, particularly if you were doing the arm business, it rustled'. When I asked her how that made her feel, she said, 'I loved that. You know. Again, it's like, we used to wear large, clanking bracelets and they'd drive you mad...'. Pamela, who worked in fashion, is aware that within fashion circles great emphasis is placed on dressing well and in an interesting way, wanting others to notice their clothes, and through this, establish their status. Therefore, to make an impact within this context requires something that will make an extraordinary impression and sound can provide that. She remembers:

The noise, you know. But that was a terribly fashion-y thing because, eventually, when I got to know fashion editors, they liked making noise. You know it’s like, they liked showing people they were in the room and clank, clank on the table or the desk is just part of it, you know? It's like, 'I've arrived. You can hear me coming down the corridor'. It's the shoes. And it's the bracelet. You know. Of course, it's on the phone as well but, you know...but that's the....all those things.

Additionally, more private and intimate aspects of sensory dress experience, for example the touch of clothing on the skin at times gave the participants a private sense of pleasure and resistance that contradicted how others perceived their appearance and the degree to which they were conforming to the social expectations and gaze of others. The need to conform to these expectations could be balanced out through a choice of outfit that had particular sensory properties with personal meanings for the wearer. This was apparent in one participant, Susan's description of a wedding she recently attended and the outfit she eventually chose to wear.

Susan, by her own admission, had a conflicted relationship with clothes, particularly around the tension between social expectations and her own enjoyment of dress. She was quite ethically minded and disliked high street shopping, both on a practical and a moral level, but loved to find a second-hand bargain. I met her at a local clothes swap. The wedding that she described was a large family affair, taking place abroad and her daughter wanted her to buy a new outfit for it. In this instance, Susan resisted her daughter's suggestion and instead suggested wearing an old dress that she had picked up at a previous clothes swap, one she was not particularly fond of and had never worn because she disliked the synthetic fabric. To Susan's surprise her daughter thought it would be 'perfect'. Susan explained:

I just felt like laughing because it was so ridiculous. I wore that and I was actually reading a poem out at the wedding in the cathedral and she thought it was all fine...Here's a dress that I 
have never worn, never really wanted to wear particularly - I didn’t think it looked particularly nice, but she did - and it was a clothes swap (laughter).

Susan realised that:

It was her idea of what I looked like [...] it was perfectly ordinary, short-sleeved, polka dot. It was awful material I remember, Crimplene type stuff, but it didn’t matter because nobody was going to come up and feel it, nobody cared.

Susan was aware of the conflict between how she appeared to others (including her daughter) and how she thought she looked, but also how the fabric felt to wear. The feel of the Crimplene against her skin was unpleasant and symbolised the artificial. Susan did not feel this was appropriate for a wedding nor was it something she liked to wear: in fact she did not even think she looked particularly good. There is a tension here between Susan's experience and interpretation and that of her daughter, who thinks she looked perfect and assumes that her mother likes the dress. But Susan is not anxious, rather she is aware of the playful irony inherent in the situation. Both conforming yet privately resisting, Susan appeared to have made an effort, to have worn something smart and appropriate, something that was 'her', yet she would never normally have worn it. In a double irony, she loves the fact that only she can feel the Crimplene, only she knows the dress came from a clothes swap, which is in fact a private expression of her inner beliefs. Susan experiences this tension as a positive and satisfying revelation and confirmation of her own agency, subjectivity and positioning within the situation and life more generally. In this instance, she has successfully drawn upon her sensory and emotional relationship to the dress to balance out the negative pressure she felt from the social requirements of the wedding and the social gaze of her daughter and others. In this way, it is argued that private sensory aspects of dress, such as touch, can have important meanings for the wearer, meanings that may be hidden from observers and that challenge the power of the gaze.

Mark M. Smith, a sensory historian, has highlighted the historical importance of non-visual sensory dimensions of clothing, intimate aspects - such as the touch of clothing against skin - that make up the experiential minutiae of daily life. These aspects may seem trivial or mundane, but can nonetheless have wider political, as well as personal value and meaning for the wearer and for those observing them. He points out that historically, 'clothing was not simply and singularly visual; it was also tactile by definition, suggesting something important about the wearer's skin and, ergo, about his or her worth or social standing'. ' Smith outlines how the wearing of luxuriously soft materials like fur was, at certain moments in history, confined to the powerful classes in a number of cultures, yet historians have failed to appreciate the importance of this due to a focus on the 'visual'. He identified clothing as having two points of perception and meaning-making, the inside which is sensed by the body of the wearer and the 
outside which is perceived by the observer. Tim Dant, in his writing on material culture, similarly observes:

It is through experiencing the inside of a thing, through sensing and responding to its 'pushiness', that we are able to collaborate with material objects, recognizing from their inside something about the rest of the world, including ourselves as physical objects. ${ }^{\text {li }}$

The participants in my study described both sensory dress strategies and complex meanings related to the sensory dimensions of their dress. I have highlighted some of these here, but there are many more pertaining to all the senses, including vision, sound and smell that emerged in my study. This demonstrates the importance of paying attention to how garments feel on the inside to the wearer, sitting against the body, and how they sound and smell, as well as how the dressed body appears. These sensory elements work together to constitute the public presentation of self and the negotiation of individual subjectivities within social life. As previously stated, this moves away from approaching the dressed body as an object to be gazed upon and towards an appreciation of the embodied and dressed self as a meaningful, active subject. Theorising the dressed body as having a 'sensory atmosphere', and considering how an empathetic, 'ambient gaze' might complicate how dressed bodies are understood and interpreted, can enable a more nuanced understanding of the role dress plays in everyday social life. It questions the effect of the social gaze and the importance of appearance within the experience of being dressed in everyday life. Importantly, it gives agency to the wearer and values alternative experience and perspectives that challenge dominant and potentially limiting understandings of dressed experience and its social and political implications.

\section{Notes}

\footnotetext{
ii Georg Simmel, ‘Adornment', in D. Frisby and M. Featherstone (eds), Simmel on Culture (London, Thousand Oaks, New Delhi: Sage, 1997 [1908]) p. 207.

iii Mary Ellen Roach-Higgins and Joanne, B. Eicher, 'Dress and Identity’, in M. E. Roach Higgins, J. B. Eicher and K. K. P. Johnson (eds), Dress and Identity (New York: Fairchild Publications, 1995).

iv Joanne Entwistle, The Fashioned Body (Cambridge, Maiden: Polity Press, 2000).

v Sara Chong Kwan, Making Sense of Everyday Dress: Integrating Multi-sensory Experience Within Our Understanding of Contemporary Dress in the UK. Unpublished thesis (London College of Fashion, University of the Arts London, 2017). The names of all interviewees have been changed.

${ }^{v i}$ Phillip Vannini, Dennis D. Waskul and Simon Gottschalk, The Senses in Self, Society and Culture: A Sociology of the Senses (New York, Oxon: Routledge, 2012) p. 123.
} 
vii For a discussion of non-western sensory cultures, see David Howes edited collection of essays. David Howes (ed.), Empire of the Senses: The Sensual Culture Reader (Oxford, New York: Berg, 2005).

viii Roland Barthes, The Fashion System (London: Cape, 1995).

ix Alison Lurie, The Language of Clothes (New York: Henry Holt, 2000 [1981]).

x See Michel Foucault, Discipline and Punish: The Birth of the Prison. Translated by Alan Sheridan (London, New York, Victoria, Ontario, New Delhi, Auckland, Rosebank: Penguin Books, 1977).

xi Sophie Woodward, Why Women Wear What They Wear (Oxford, New York: Berg, 2007).

See also Alison Clarke and Daniel Miller, 'Fashion and Anxiety', in Fashion Theory 6/2 (2002), pp. 191-214.

xii Efrat Tseelon, The Masque of Femininity: The Presentation of Woman in Everyday Life (London, Thousand Oaks: Sage, 1995).

xiii Joanne Entwistle, 'Power Dressing and The Fashioning of the Career Woman', in L. Goodman, R. Allen, L. Janes and C. King (eds), Buy This Book: Studies in Advertising and Consumption (London: Routledge, 1997). See also Entwistle, The Fashioned Body. xiv Shaun Cole, Don We Now Our Gay Apparel: Gay Men's Dress in The Twentieth Century (London: Berg, 2000).

xv Lou Taylor, The Study of Dress History (Manchester: Manchester University Press, 2002). See also Lou Taylor, Establishing Dress History (Manchester, 2004).

xvi Woodward, Why Women Wear What They Wear.

xvii Lucia Ruggerone, 'The Feeling of Being Dressed: Affect Studies and the Clothes Body', Fashion Theory 21/5 (2016), pp. 573-593.

xviii The following section on the turn towards embodiment is developed from my earlier writing on 'Embodied Research Methods' published in the SAGE Research Methods Foundations series, part of The SAGE Encyclopedia of Research Methods (Sage, 2019).

xix Don Welton (ed), The Body: Classic and Contemporary Readings (Massachusetts, Oxford: John Wiley \& Sons, 1999).

xx Entwistle, The Fashioned Body, pp. 12-13.

${ }^{x x i}$ Colin Campbell, 'When the Meaning is Not a Message: A Critique of the Consumption as Communication Thesis', in M. Barnard (ed), Fashion Theory: A Reader (Oxon, New York: Routledge, 2007). xxii Ibid., p. 166.

xxiii Entwistle, The Fashioned Body, p. 9.

${ }^{\text {xxiv }}$ Here 'haptic' describes how the body experiences and is affected by the feel of dress moving against and touching or pressing upon the body.

${ }^{x x v}$ Llewellyn Negrin, 'Maurice Merleau-Ponty: The Corporeal Experience of Fashion', in A. Rocamora and A. Smelik (eds), Thinking Through Fashion (London, New York: I.B. Taurus, 2016) pp. 115-116. xxvi Maurice Merleau-Ponty, 'Eye and Mind’, in G.A. Johnson (ed), The Merleau-Ponty Aesthetics Reader (Illinois: Northwestern University Press, 1993 [1964]) p. 124.

xxvii www.sensorystudies.org.

xxviii Howes, Empire of the Senses.

xxix Peter McNeil, 'George Simmel: The 'Philosophical Monet', in A. Rocamora and A. Smelik (eds), Thinking Through Fashion: A Guide to Key Theorists (London and New York: I. B. Taurus, 2016) p. 66. 
${ }^{\mathrm{xxx}}$ Ibid. p.71

xxxi Ibid., p. 109.

xxxii Ibid., p. 111.

xxxiii Jennifer Mason, The Socio-Atmospherics of Weather (2015) [Internet] Available at

http://www.socialsciences.manchester.ac.uk/morgancentre/events/atmospheres/ (accessed 29 April 1996). xxxiv Susan Bordo, Unbearable Weight: Feminism, Western Culture and the Body (Berkeley, Los Angeles, London: University of California Press, 2003 [1993]), p. 35.

xxxv Sarah Pink, Doing Sensory Ethnography (London, California, New Delhi, Singapore: Sage, 2009) p. 136.

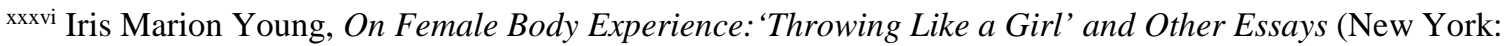
Oxford University Press, 2005 [1988]) p. 643.

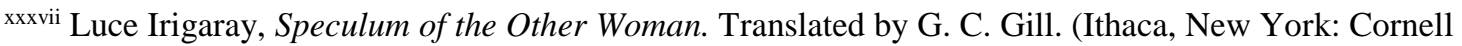
University Press, 1985).

xxxviii Luce Irigarary quoted in I.M. Young, On Female Body Experience: ‘Throwing Like a Girl’ and Other Essays (New York: Oxford University Press, 2005 [1988]), p. 68.

xxxix Ruggerone, ‘The Feeling of Being Dressed: Affect Studies and the Clothes Body’, pp. 573-593.

${ }^{\mathrm{xl}}$ Daniel Miller, 'Introduction', in S. Kuchler and D. Miller (eds) Clothing as Material Culture (Oxford, New York: Berg, 2005). p. 3.

xli Howes, Empire of the Senses, p. 10.

xlii Young, ‘Women Recovering Our Clothes’ p. 73.

xliii Elizabeth Wilson, Adorned in Dreams (London, New York: I.B. Taurus, 2003 [1985]).

xliv Agnès Rocamora, 'Fields of Fashion: Critical Insights Into Bourdieu’s Sociology of Culture’, Journal of Consumer Culture 2/3 (2002), pp. 341-362.

xlv Wilson, Adorned in Dreams, p. 13.

${ }^{x l v i}$ Mark Paterson, The Senses of Touch: Haptics, Affects and Technologies (Oxford, New York: Berg, 2007) p. 2.

xlvii Kaja Silverman, 'Fragments of a Fashionable Discourse’, in S. Benstock and S. Ferriss (eds), On Fashion (New Jersey: Rutgers University Press, 1994 [1986]) p. 193.

xlviii Paul Sweetman, 'Shop-window dummies?', in J. Entwistle and E. Wilson (eds), Body Dressing (Oxford, New York: Berg, 2001) p. 67.

xlix Erving Goffman, The Presentation of Self in Everyday Life (London, New York, Victoria,

Toronto, New Delhi, Albany, Rosebank: Penguin Books, 1990 [1959]).

${ }^{1}$ Mark, M. Smith, Sensory History (Oxford, New York: Berg, 2007) p. 106.

li Tim Dant, Material Culture in the Social World: Values, Activities, Lifestyles (Buckingham, Philadelphia: Open University Press, 1999) p. 123.

\section{Bibliography}

Barthes Roland, The Fashion System (London: Cape, 1995). 
Bordo Susan, Unbearable Weight: Feminism, Western Culture and the Body (Berkeley, Los Angeles, London: University of California Press, 2003 [1993]).

Campbell Colin, 'When the Meaning is Not a Message: A Critique of the Consumption as Communication Thesis', in M. Barnard (ed), Fashion Theory: A Reader (Oxon, New York: Routledge, 2007).

Chong Kwan Sara, Making Sense of Everyday Dress: Integrating Multi-sensory Experience Within Our Understanding of Contemporary Dress in the UK. Unpublished thesis (London College of Fashion, University of the Arts London, 2017).

Chong Kwan Sara, 'Embodied Research Methods', in The SAGE Encyclopedia of Research Methods (Sage, 2019).

Clarke Alison and Miller Daniel, 'Fashion and Anxiety', in Fashion Theory 6/2 (2002), pp. 191214.Cole, S. (2000) Don We Now Our Gay Apparel: Gay Men's Dress in The Twentieth Century. London: Berg.

Cole Shaun, Don We Now Our Gay Apparel: Gay Men's Dress in The Twentieth Century (London: Berg, 2000).

Dant Tim, Material Culture in the Social World: Values, Activities, Lifestyles (Buckingham, Philadelphia: Open University Press, 1999).

Entwistle, Joanne, 'Power Dressing and The Fashioning of the Career Woman', in L. Goodman, R. Allen, L. Janes and C. King (eds), Buy This Book: Studies in Advertising and Consumption (London: Routledge, 1997).

- The Fashioned Body (Cambridge, Maiden: Polity Press, 2000).

Foucault Michel, Discipline and Punish: The Birth of the Prison. Translated by Alan Sheridan (London, New York, Victoria, Ontario, New Delhi, Auckland, Rosebank: Penguin Books, 1977).

Goffman Erving, The Presentation of Self in Everyday Life (London, New York, Victoria, Toronto, New Delhi, Albany, Rosebank: Penguin Books, 1990 [1959]).

Howes David (ed.), Empire of the Senses: The Sensual Culture Reader (Oxford, New York: Berg, 2005).

Irigaray Luce, Speculum of the Other Woman. Translated by G. C. Gill. (Ithaca, New York: Cornell University Press, 1985).

Lurie Alison, The Language of Clothes (New York: Henry Holt, 2000 [1981]).

Mason Jennifer, The Socio-Atmospherics of Weather (2015) [Internet] Available at: http://www.socialsciences.manchester.ac.uk/morgancentre/events/atmospheres/ [Accessed 29 April 1996].

Miller Daniel, 'Introduction’, in S. Kuchler and D. Miller (eds) Clothing as Material Culture (Oxford, New York: Berg, 2005). 
McNeil Peter, 'George Simmel: The 'Philosophical Monet', in A. Rocamora and A. Smelik (eds), Thinking Through Fashion: A Guide to Key Theorists (London and New York: I. B. Taurus, 2016).

Merleau-Ponty Maurice, 'Eye and Mind', in G.A. Johnson (ed), The Merleau-Ponty Aesthetics Reader (Illinois: Northwestern University Press, 1993 [1964]).

Negrin Llewellyn, 'Maurice Merleau-Ponty: The Corporeal Experience of Fashion’, in A. Rocamora and A. Smelik (eds), Thinking Through Fashion (London, New York: I.B. Taurus, 2016).

Paterson Mark, The Senses of Touch: Haptics, Affects and Technologies (Oxford, New York: Berg, 2007).

Pink, Sarah, Doing Sensory Ethnography (London, California, New Delhi, Singapore: Sage, 2009)

Roach-Higgins Mary-Ellen and Eicher Joanne B., 'Dress and Identity', in M. E. Roach Higgins, J. B. Eicher and K. K. P. Johnson (eds), Dress and Identity (New York: Fairchild Publications, 1995).

Rocamora Agnès, ‘Fields of Fashion: Critical Insights Into Bourdieu’s Sociology of Culture’, Journal of Consumer Culture 2/3 (2002), pp. 341-362.

Ruggerone Lucia, 'The Feeling of Being Dressed: Affect Studies and the Clothes Body', Fashion Theory 21/5 (2016), pp. 573-593.

Silverman Kaja, 'Fragments of a Fashionable Discourse', in S. Benstock and S. Ferriss (eds), On Fashion (New Jersey: Rutgers University Press, 1994 [1986]).

Simmel Georg, 'Adornment', in D. Frisby and M. Featherstone (eds), Simmel on Culture (London, Thousand Oaks, New Delhi: Sage, 1997 [1908]).

- 'The Sociology of The Senses' in D. Frisby and M. Featherstone (eds) Simmel on Culture (London, Thousand Oaks, New Delhi: Sage, 1997 [1908]).

Smith Mark M., Sensory History (Oxford, New York: Berg, 2007).

Sweetman Paul, 'Shop-window dummies?', in J. Entwistle and E. Wilson (eds), Body Dressing (Oxford, New York: Berg, 2001).

Taylor Lou, The Study of Dress History (Manchester: Manchester University Press, 2002).

- Establishing Dress History (Manchester, 2004).

Tseelon Efrat, The Masque of Femininity: The Presentation of Woman in Everyday Life (London, Thousand Oaks: Sage, 1995).

Vannini Phillip, Waskul Dennis D. and Gottschalk Simon, The Senses in Self, Society and Culture: A Sociology of the Senses (New York, Oxon: Routledge, 2012).

Welton Don (ed), The Body: Classic and Contemporary Readings (Massachusetts, Oxford: John Wiley \& Sons, 1999).

Wilson Elizabeth, Adorned in Dreams (London, New York: I.B. Taurus, 2003 [1985]).

Woodward Sophie, Why Women Wear What They Wear (Oxford, New York: Berg, 2007). 
Young Iris Marion, On Female Body Experience: 'Throwing Like a Girl' and Other Essays (New York: Oxford University Press, 2005 [1988]). 